\title{
Heterogeneously Catalyzed Phosphine-Free Heck Cross-Coupling Reaction of Aryl Halides with Reusable Palladium(II) Schiff Base Complex
}

\author{
Manirul Islam, ${ }^{*, a}$ Paramita Mondal, ${ }^{a}$ Kazi Tuhina ${ }^{b}$ and Anupam S. Roy ${ }^{a}$ \\ ${ }^{a}$ Department of Chemistry, University of Kalyani, Kalyani, Nadia, 741235, W.B. India \\ ${ }^{b}$ Department of Chemistry, B.S. College, S-24 P.G.S., 743329, W.B. India
}

\begin{abstract}
$\mathrm{O}$ acoplamento entre haletos de arila e terminais alceno (reação de Heck) foi investigado na presença de catalisadores de paládio (II) suportados em poliestirenos contendo bases de Schiff. O catalisador é estável frente ao ar e umidade, e tem atividade catalítica significativa nas reações de acoplamento cruzado de Heck sob condições normais. Vários haletos de arila e alcenos terminais foram facilmente acoplados na presença de ar, fornecendo os correspondentes produtos de acoplamaneto cruzado, em ótimos rendimentos. $\mathrm{O}$ catalisador é facilmente recuperado quantitativamente por filtração simples e reutilizado por até sete ciclos sem perda de atividade.
\end{abstract}

The coupling between aryl halides with terminal alkenes (Heck reaction) has been investigated in the presence of a polystyrene-supported Schiff base palladium(II) catalyst. The present catalyst is air and moisture-stable and has significant catalytic activity in Heck cross-coupling reactions under operating conditions. Various aryl halides and terminal alkenes were coupled smoothly under air, to afford the corresponding cross-coupled products in excellent yields. Furthermore, the catalyst can be easily recovered quantitatively by simple filtration and reused up to seven cycles without losing its activity.

Keywords: polystyrene, schiff base, palladium(II) complex, heterogeneous catalysis, Heck reaction

\section{Introduction}

Transition metal-catalyzed carbon-carbon bond forming reactions are widely employed methods in modern organic chemistry. ${ }^{1-3}$ The use of such catalytic procedures has found applications in the preparation of many natural products, as well as in materials science and the agrochemical industry. ${ }^{4-7}$ With various metals being employed in coupling reactions, palladium probably is the most frequently chosen transition metal due to its excellent catalytic efficiency in this type of reactions..$^{8-12}$ The palladium catalyzed Heck cross-coupling reaction of aryl halides with terminal alkenes, which provides a powerful tool for the formation of aryl-alkenes, ${ }^{13-15}$ has been widely applied to such diverse areas as natural product syntheses and material sciences. The most common catalytic system used for this reaction is the homogeneous palladium-phosphine complexes ${ }^{16-20}$ as $\mathrm{PdCl}_{2}\left(\mathrm{PPh}_{3}\right)_{2}$ or $\mathrm{Pd}\left(\mathrm{PPh}_{3}\right)_{4}$ in presence of base. One key challenge for the commercial development and practical use

\footnotetext{
*e-mail: manir65@rediffmail.com
}

of homogeneous phosphine catalysts is the contamination of products by palladium-phosphine and separation of products from the catalytic media. From an industrial as well as an economic standpoint, a phosphine-free process would provide much needed impetus to the development of improved catalyst systems for Heck couplings. ${ }^{21-25}$ Further, such a process would be advantageous for synthetic chemists who would generally prefer not to use expensive and air-sensitive phosphine ligands. In addition, the elimination of phosphines would be welcome because industrial wastes containing them would require treatment for environmental purposes.

The heterogenization of homogeneous catalytic reactions has attracted great attention from a wide range of organic chemists over the last few decades. ${ }^{26-30}$ Immobilizations of homogeneous catalysts into insoluble polymeric supports by covalent bonding or complexation enables the easy recovery and reuse of catalysts. Polystyrene is one of the most widely employed macromolecular supports. ${ }^{31-34}$ This supported material offers several advantageous features in heterogeneous catalysis such as thermal stability, selectivity 


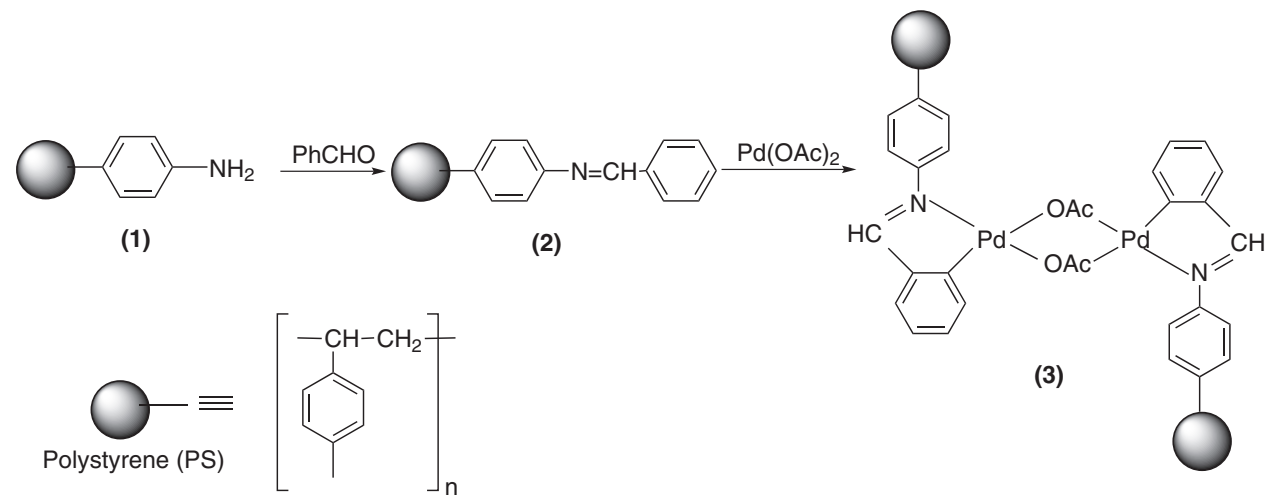

Scheme 1. Synthesis of polymer-anchored Pd(II) Schiff base complex.

and recyclability to homogeneous systems and ease of their separation from the reaction products also leading to operational flexibility.

Our continuing interest in palladium-catalyzed organic transformations ${ }^{35-38}$ prompted us to extend our attention to the palladium catalyzed Heck reaction. Herein we have reported an efficient procedure for a heterogeneous phosphine-free Heck cross-coupling reaction of aryl halides with terminal alkenes using PS- $\left[\left(\mathrm{C}_{6} \mathrm{H}_{4} \mathrm{CH}=\mathrm{N}\right) \mathrm{Pd}(\mathrm{OAc})\right]_{2}$ as the catalyst and $\mathrm{K}_{2} \mathrm{CO}_{3}$ as the base.

\section{Results and Discussion}

The outline for the preparation of the polymer-anchored Schiff base complex is presented in Scheme 1. It was readily prepared through a two-step procedure. ${ }^{36}$ Firstly, the polystyrene amine (1) $(1 \mathrm{~g})$ was reacted with benzaldehyde $(3 \mathrm{~mL})$ in dry toluene $(10 \mathrm{~mL})$ under reflux condition for $72 \mathrm{~h}$ to afford polymer Schiff base ligand (2). This polymeranchored Schiff base ligand $(1 \mathrm{~g})$ subsequently reacted with palladium acetate $(0.5 \mathrm{~g})$ in acetic acid $(10 \mathrm{~mL})$ at $80^{\circ} \mathrm{C}$ for $10 \mathrm{~h}$ to generate the corresponding polystyrene-supported palladium(II) complex (3).

Due to insolubility of the polymer-anchored Pd(II) complex in all common organic solvents, its structural investigations was limited only to its physico-chemical properties, scanning electron microscope-microprobe analyses (SEM-EDX), thermogravimetric-differential thermal (TGA-DTA), infrared (IR) and ultraviolet-visible (UV-Vis) spectral data. The complete incorporation of the organic substructure in the material was confirmed by elemental analysis. The metal content of polymeranchored Pd(II) complex determined by atomic absorption spectrophotometer (AAS) suggested $2.23 \mathrm{wt} \%$ metal loading in the immobilized palladium complex. In Figure 1 the FE SEM image of polystyrene anchored Schiff base ligand (Figure 1A) and anchored palladium complex
(Figure 1B) is shown. The SEM images of polymeranchored ligand and metal complex clearly shows the morphological change which occurred on the surface of the polymer matrix after loading of the metal (Figure 1). Flake like particles are observed in case of polymeranchored ligand. After metal loading spherical shape of the particles are quite visible throughout the specimen. Further EDX analysis of polymer-anchored metal complex shows palladium content along with $\mathrm{C}$ which suggested the formation of metal complex with the anchored ligand. The EDX profile of catalyst is presented in Figure 2.

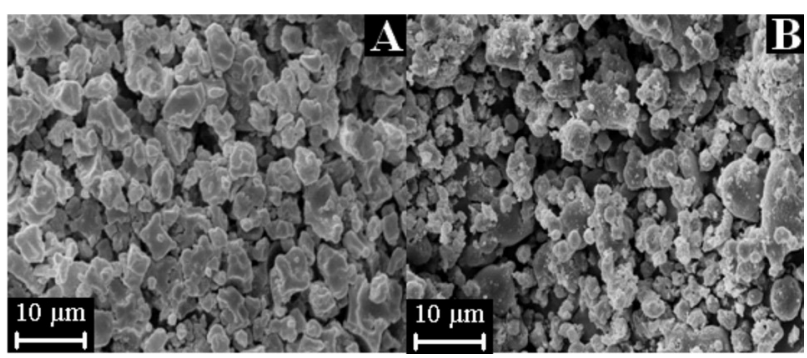

Figure 1. FE SEM image of polymer-anchored Schiff base ligand (A) and polymer-anchored palladium(II) Schiff base complex (B).

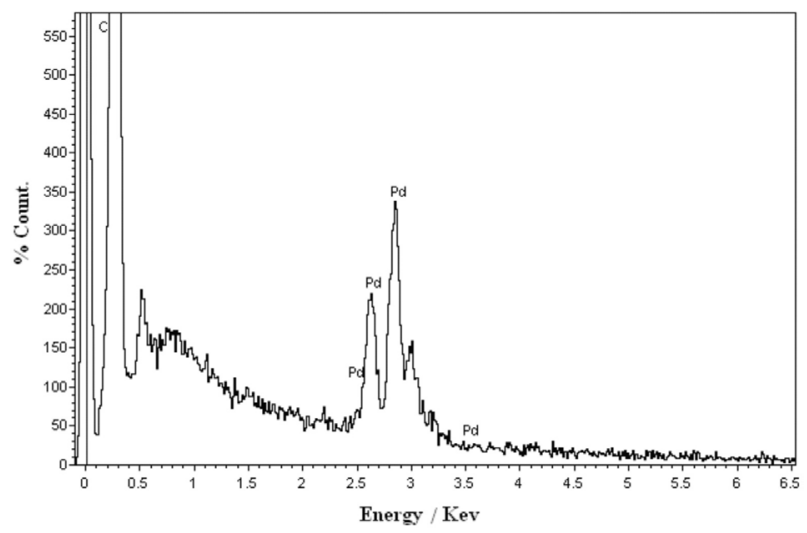

Figure 2. EDX spectrum of $\mathrm{PS}\left[\left(\mathrm{C}_{6} \mathrm{H}_{4} \mathrm{CH}=\mathrm{N}\right) \mathrm{Pd}(\mathrm{OAc})\right]_{2}$ complex. 
The catalyst is thermally stable up to $250{ }^{\circ} \mathrm{C}$. The IR spectrum of polymer-anchored Schiff base ligand showed characteristic IR peak at $1635 \mathrm{~cm}^{-1}$ may be assigned to the $-\mathrm{C}=\mathrm{N}$ stretching vibration of imine which on complexation shifted towards lower frequency to $1615 \mathrm{~cm}^{-1}$ suggested bond formation between Pd and ligand. Other characteristic peaks at 1585, $1430 \mathrm{~cm}^{-1}$ (vCOO bridged), ${ }^{39} 720 \mathrm{~cm}^{-1}$ (orthometallation), ${ }^{40}$ and $455 \mathrm{~cm}^{-1}(\mathrm{vPd}-\mathrm{N})^{41}$ also support the formation of palladium(II) complex. The UV-Vis spectra provided further evidence for the presence of palladium on polymer support. The absorption maxima at $295 \mathrm{~nm}$ may be attributed to the $\pi \rightarrow \pi^{*}$ transition in polymer and phenyl moiety and the absorption at higher range $(370-440 \mathrm{~nm})$ may be due to the $\pi \rightarrow \pi^{*}$ and $n \rightarrow \pi^{*}$ transitions of imine system in conjugation with the aromatic nuclei.

In order to evaluate the catalytic activity of the polystyrene-supported palladium(II) Schiff base complex, the Heck cross coupling reaction of aryl halides with terminal alkenes was studied (Scheme 2). Initially, to determine the optimum reaction conditions, the influences of metal precursors, temperatures, solvents, bases, base-substrate ratio and amounts of the catalyst on the catalytic property of the present palladium complex were investigated taking the reaction of 4-bromonitrobenzene with styrene as model reaction. Since no air-sensitive phosphine was used, all the coupling reactions were conducted under air atmosphere.

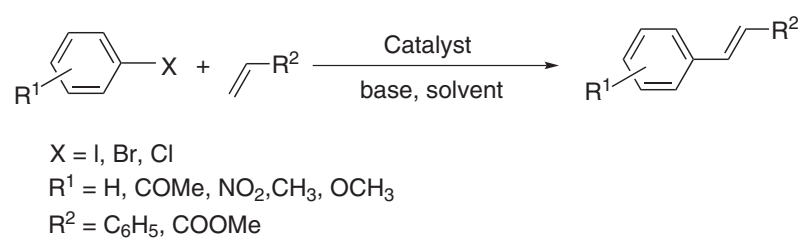

Scheme 2. Heck cross-coupling reaction.

The reaction temperature has a very strong influence on the Heck reaction. No product formation was observed at room temperature. As the temperature increased gradually from $30-90{ }^{\circ} \mathrm{C}$, the conversion of 4-bromonitrobenzene increased. We found that the reaction performed at $90{ }^{\circ} \mathrm{C}$ appeared to provide the best result and highest yield of coupled product was obtained (Figure 3 ).

The catalytic performance of a coupling reaction is also greatly affected by the particular metal precursors employed. $\mathrm{Pd}(\mathrm{OAc})_{2}$ and $\mathrm{PdCl}_{2}$ as metal precursors attached with polystyrene anchored Schiff base ligand were studied for the coupling reaction of 4-bromonitrobenzene and styrene. As shown in Table 1, an excellent yield was obtained with $\mathrm{Pd}(\mathrm{OAc})_{2}$ as palladium source (Table 1, entry 3). Unexpectedly, the commonly used

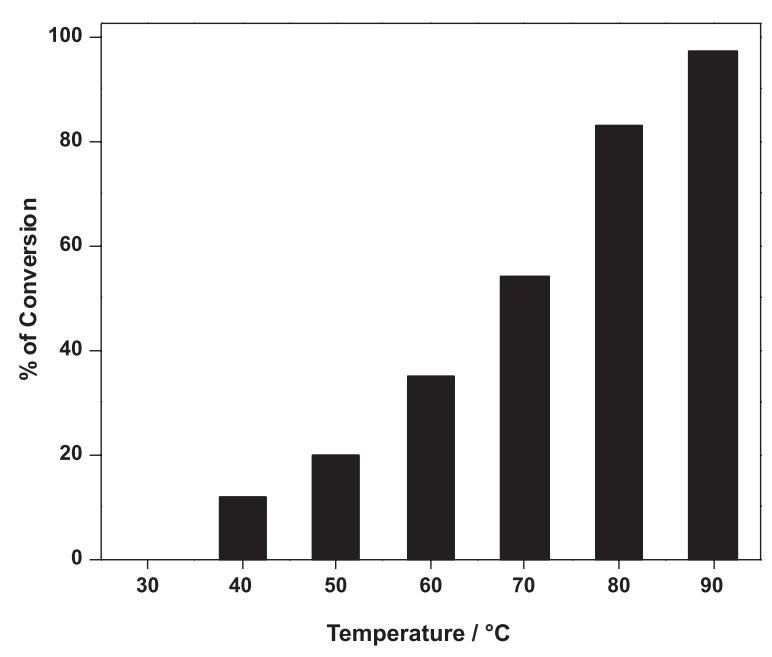

Figure 3. The influence of reaction temperature on Heck cross-coupling reaction.

$\mathrm{PdCl}_{2}$ did not show competitive result in this case (Table 1, entry 5). Using metal salts without any ligand gave partial conversion of the substrate (Table 1, entries 6, 7). A control experiment indicated that the coupling reaction did not occur in the absence of catalyst (Table 1, entry 18).

Another essential factor which affects the performance of a catalytic reaction is the amount of catalyst used. In order to optimize the catalyst amount, different amounts of catalyst were used in the coupling reaction of 4-bromonitrobenzene with styrene. The results are presented in Table 1 (entries 1-4). The best results were obtained with $0.5 \mathrm{~mol} \%$ of Pd catalyst (Table 1, entry 3 ).

The Heck cross coupling reaction was found to be highly dependent on the nature of solvent. As reported in literature, polar aprotic solvents tend to give the best results for the Heck coupling reaction. ${ }^{42,43}$ We employed several solvents in the Heck model reaction. Among evaluated polar and nonpolar solvents, dimethylformamide (DMF) was the most productive solvent (Table 1, entry 3) which is consistent with the previous report. Other polar aprotic solvents, such as dimethylsulfoxide (DMSO) and acetonitrile (MeCN), gave moderate conversion (Table 1, entries 9, 10). Non polar solvent, such as toluene, affords very poor conversion (Table 1, entry 11). Extensive application of eco-friendly solvents such as water in chemical reaction is a touching appeal of green chemistry. ${ }^{4-46} \mathrm{We}$ also performed the model coupling reaction in neat water but yield was not satisfactory (Table 1, entry 12). A mixed solvent system, however, did show better result (Table 1, entry 13).

The effect of base on the catalytic performance of this system was investigated by taking the model reaction in different bases. Among several organic and inorganic bases, potassium carbonate $\left(\mathrm{K}_{2} \mathrm{CO}_{3}\right)$ was found to be the 
Table 1. Optimal reaction conditions for Heck cross-coupling reaction of 4-bromo nitrobenzene and styrene ${ }^{\mathrm{a}}$

\begin{tabular}{|c|c|c|c|c|c|c|c|}
\hline entry & Catalyst & $\begin{array}{l}\text { Cat. Conc. } \\
\mathrm{mol} \% \text { of Pd }\end{array}$ & Solvent & Base & Base:Substrate & time (h) & Yield $^{\mathrm{b}}(\%)$ \\
\hline 1 & $\mathrm{PS}\left[\left(\mathrm{C}_{6} \mathrm{H}_{4} \mathrm{CH}=\mathrm{N}\right) \mathrm{Pd}(\mathrm{OAc})\right]_{2}$ & 0.1 & DMF & $\mathrm{K}_{2} \mathrm{CO}_{3}$ & $2: 1$ & 8 & 23 \\
\hline 2 & $\mathrm{PS}\left[\left(\mathrm{C}_{6} \mathrm{H}_{4} \mathrm{CH}=\mathrm{N}\right) \mathrm{Pd}(\mathrm{OAc})\right]_{2}$ & 0.25 & DMF & $\mathrm{K}_{2} \mathrm{CO}_{3}$ & $2: 1$ & 8 & 70 \\
\hline 3 & $\mathrm{PS}\left[\left(\mathrm{C}_{6} \mathrm{H}_{4} \mathrm{CH}=\mathrm{N}\right) \mathrm{Pd}(\mathrm{OAc})\right]_{2}$ & 0.5 & DMF & $\mathrm{K}_{2} \mathrm{CO}_{3}$ & $2: 1$ & 8 & 97 \\
\hline 4 & $\mathrm{PS}\left[\left(\mathrm{C}_{6} \mathrm{H}_{4} \mathrm{CH}=\mathrm{N}\right) \mathrm{Pd}(\mathrm{OAc})\right]_{2}$ & 0.75 & DMF & $\mathrm{K}_{2} \mathrm{CO}_{3}$ & $2: 1$ & 8 & 97 \\
\hline 5 & $\mathrm{PS}\left[\left(\mathrm{C}_{6} \mathrm{H}_{4} \mathrm{CH}=\mathrm{N}\right) \mathrm{Pd}(\mathrm{Cl})\right]_{2}$ & 0.5 & DMF & $\mathrm{K}_{2} \mathrm{CO}_{3}$ & $2: 1$ & 8 & 69 \\
\hline 6 & $\mathrm{Pd}(\mathrm{OAc})_{2}$ & 0.5 & DMF & $\mathrm{K}_{2} \mathrm{CO}_{3}$ & $2: 1$ & 8 & 63 \\
\hline 7 & $\mathrm{PdCl}_{2}$ & 0.5 & DMF & $\mathrm{K}_{2} \mathrm{CO}_{3}$ & $2: 1$ & 8 & 48 \\
\hline 8 & $\mathrm{PS}\left[\left(\mathrm{C}_{6} \mathrm{H}_{4} \mathrm{CH}=\mathrm{N}\right) \mathrm{Pd}(\mathrm{OAc})\right]_{2}$ & 0.5 & $\mathrm{DMF}$ & $\mathrm{K}_{2} \mathrm{CO}_{3}$ & $1: 1$ & 8 & 52 \\
\hline 9 & $\mathrm{PS}\left[\left(\mathrm{C}_{6} \mathrm{H}_{4} \mathrm{CH}=\mathrm{N}\right) \mathrm{Pd}(\mathrm{OAc})\right]_{2}$ & 0.5 & DMSO & $\mathrm{K}_{2} \mathrm{CO}_{3}$ & $2: 1$ & 8 & 85 \\
\hline 10 & $\mathrm{PS}\left[\left(\mathrm{C}_{6} \mathrm{H}_{4} \mathrm{CH}=\mathrm{N}\right) \mathrm{Pd}(\mathrm{OAc})\right]_{2}$ & 0.5 & $\mathrm{MeCN}$ & $\mathrm{K}_{2} \mathrm{CO}_{3}$ & $2: 1$ & 8 & 76 \\
\hline 11 & $\mathrm{PS}\left[\left(\mathrm{C}_{6} \mathrm{H}_{4} \mathrm{CH}=\mathrm{N}\right) \mathrm{Pd}(\mathrm{OAc})\right]_{2}$ & 0.5 & Toluene & $\mathrm{K}_{2} \mathrm{CO}_{3}$ & $2: 1$ & 8 & 18 \\
\hline 12 & $\mathrm{PS}\left[\left(\mathrm{C}_{6} \mathrm{H}_{4} \mathrm{CH}=\mathrm{N}\right) \mathrm{Pd}(\mathrm{OAc})\right]_{2}$ & 0.5 & $\mathrm{H}_{2} \mathrm{O}$ & $\mathrm{K}_{2} \mathrm{CO}_{3}$ & $2: 1$ & 8 & 11 \\
\hline 13 & $\mathrm{PS}\left[\left(\mathrm{C}_{6} \mathrm{H}_{4} \mathrm{CH}=\mathrm{N}\right) \mathrm{Pd}(\mathrm{OAc})\right]_{2}$ & 0.5 & $\mathrm{H}_{2} \mathrm{O}-\mathrm{DMF}$ & $\mathrm{K}_{2} \mathrm{CO}_{3}$ & $2: 1$ & 8 & 45 \\
\hline 14 & $\mathrm{PS}\left[\left(\mathrm{C}_{6} \mathrm{H}_{4} \mathrm{CH}=\mathrm{N}\right) \mathrm{Pd}(\mathrm{OAc})\right]_{2}$ & 0.5 & DMF & $\mathrm{Na}_{2} \mathrm{CO}_{3}$ & $2: 1$ & 8 & 83 \\
\hline 15 & $\mathrm{PS}\left[\left(\mathrm{C}_{6} \mathrm{H}_{4} \mathrm{CH}=\mathrm{N}\right) \mathrm{Pd}(\mathrm{OAc})\right]_{2}$ & 0.5 & DMF & $\mathrm{NaOH}$ & $2: 1$ & 8 & 70 \\
\hline 16 & $\mathrm{PS}\left[\left(\mathrm{C}_{6} \mathrm{H}_{4} \mathrm{CH}=\mathrm{N}\right) \mathrm{Pd}(\mathrm{OAc})\right]_{2}$ & 0.5 & DMF & $\mathrm{K}_{3} \mathrm{PO}_{4}$ & $2: 1$ & 8 & 73 \\
\hline 17 & $\mathrm{PS}\left[\left(\mathrm{C}_{6} \mathrm{H}_{4} \mathrm{CH}=\mathrm{N}\right) \mathrm{Pd}(\mathrm{OAc})\right]_{2}$ & 0.5 & DMF & $\mathrm{Et}_{3} \mathrm{~N}$ & $2: 1$ & 8 & 39 \\
\hline 18 & No catalyst & 0.5 & DMF & $\mathrm{K}_{2} \mathrm{CO}_{3}$ & $2: 1$ & 24 & No reaction \\
\hline 19 & $\mathrm{PS}\left[\left(\mathrm{C}_{6} \mathrm{H}_{4} \mathrm{CH}=\mathrm{N}\right) \mathrm{Pd}(\mathrm{OAc})\right]_{2}$ & 0.5 & DMF & No base & - & 24 & No reaction \\
\hline
\end{tabular}

a Reaction conditions: 4-bromonitrobenzene $(1.0 \mathrm{mmol})$, styrene $(2.0 \mathrm{mmol})$, solvent $(6 \mathrm{~mL})$; all the reactions were carried out in air. ${ }^{\mathrm{b}} \mathrm{Conversion}$ of reactant was determined by GC and GC MS analysis using dodecane as internal standard.

most effective base as highest conversion was obtained and thus chosen as the preferred base for the reactions (Table 1, entry 3). Other inorganic bases were less effective and affords moderate yield of coupled product (Table 1, entries 14-16). Low conversion was achieved when organic base, triethylamine $\left(\mathrm{Et}_{3} \mathrm{~N}\right)$, was used (Table 1, entry 17). This may be due in part to blocking of free coordination sites on the palladium center. ${ }^{47,48}$ The base substrate mole ratio also has a significant influence in the Heck coupling reaction. Two different mole-ratios were tested (Table 1) and among them, 2:1 mole ratio of base: substrate (Table 1, entry 3 ) was found to be best. It was observed that rate of the reaction drops significantly with decrease the ratio to $1: 1$ (Table 1 , entry 8).

Under these optimized reaction conditions, a variety of electronically and structurally diverse aryl halides could be coupled very efficiently with terminal alkenes, affording the desired products in excellent yields. Styrene gave the corresponding coupled product in higher yields than methyl acrylate. Non-substituted aryl halides, iodobenzene and bromobenzene, gave excellent yield of coupled product
(Table 2, entries 1, 2, 11, 12). Aryl bromides bearing an electron-withdrawing group can be employed to generate the desired product by coupling with styrene and methyl acrylate in excellent yield (Table 2, entries 3, 4, 13, 14). Aryl bromides containing electron-donating groups required longer reaction time to obtain high yields (Table 2, entries 5, 6, 15, 16). 3-Bromopyridine (Table 2, entries 7, 17) and sterically hindered 1-bromo-naphthalene (Table 2, entries 8,18 ) could provide the corresponding products in good yields. In all coupled product, $E$-stereochemistry was obtained. For the electron-neutral aryl chloride, the catalyst was inefficient and the conversion of chlorobenzene was very low (Table 2, entries 9, 19). However, the coupling of electron-deficient aryl chloride, 4-chloroacetophenone, provided a moderate yield (Table 2, entries 10, 20).

For comparison, the catalytic activity of the present polymer-anchored catalyst $\operatorname{PS}\left[\left(\mathrm{C}_{6} \mathrm{H}_{4} \mathrm{CH}=\mathrm{N}\right)\right.$ $\mathrm{Pd}(\mathrm{OAc})]_{2}$ and corresponding homogeneous catalyst $\left[\left(\mathrm{C}_{6} \mathrm{H}_{4} \mathrm{CH}=\mathrm{N}\right) \mathrm{Pd}(\mathrm{OAc})\right]_{2}$ were examined for the reaction of 4-bromonitrobenzene with styrene. As revealed in Table 3, compatible performances were observed for both systems 
(Table 3, entries 1 and 2). Polymer-anchored catalyst gets advantages due to its recycling and reusable properties. Thermal stability of the present heterogeneous catalyst is higher than its homogeneous analogue and the catalyst can withstand in more drastic reaction than homogeneous catalyst. We also compared the catalytic activity of the present catalyst with other reported system. It is seen that present catalyst exhibited higher conversions and yields compared to the other reported system ${ }^{49,50}$ (Table 3, entries 3 and 4). In addition, the necessary reaction temperature is lower and lower reaction time is required.

Hot-filtration test was performed in the Heck crosscoupling reaction of 4-bromonitrobenzene with styrene to investigate whether the reaction proceeded in a heterogeneous or a homogeneous fashion. After continuing the reaction for $4 \mathrm{~h}$, the catalyst was removed by filtration and the determined conversion was $46 \%$. The resulting filtrate was subjected to heating for further $4 \mathrm{~h}$. From gas chromatography (GC) result it reveals that after separation of the catalyst no conversion takes place in the filtrate part. This confirms that the reaction did not proceed upon the removal of the solid catalyst. Further, no evidence for leaching of palladium or decomposition of the complex catalyst was observed during the catalytic reaction and no palladium could be detected by atomic absorption spectroscopic measurement of the filtrate after removal of catalyst. These studies clearly demonstrated that palladium was intact to a considerable extent with the heterogeneous support, and no significant amount of leaching occurred during reaction.

The advantage of the heterogeneous catalysis is the possibility of recovering and reusing the catalyst during the reaction. We studied the reusability of the present heterogeneous palladium catalyst in the Heck cross-coupling reaction taking the reaction of 4-bromonitrobenzene and styrene. After completion

Table 2. Heck reaction of aryl halides with terminal alkenes using $\mathrm{PS}\left[\left(\mathrm{C}_{6} \mathrm{H}_{4} \mathrm{CH}=\mathrm{N} \mathrm{P}\right) \mathrm{Pd}(\mathrm{OAc})\right]_{2}$ complex catalyst $^{\mathrm{a}}$

entry


Table 2. Continuation

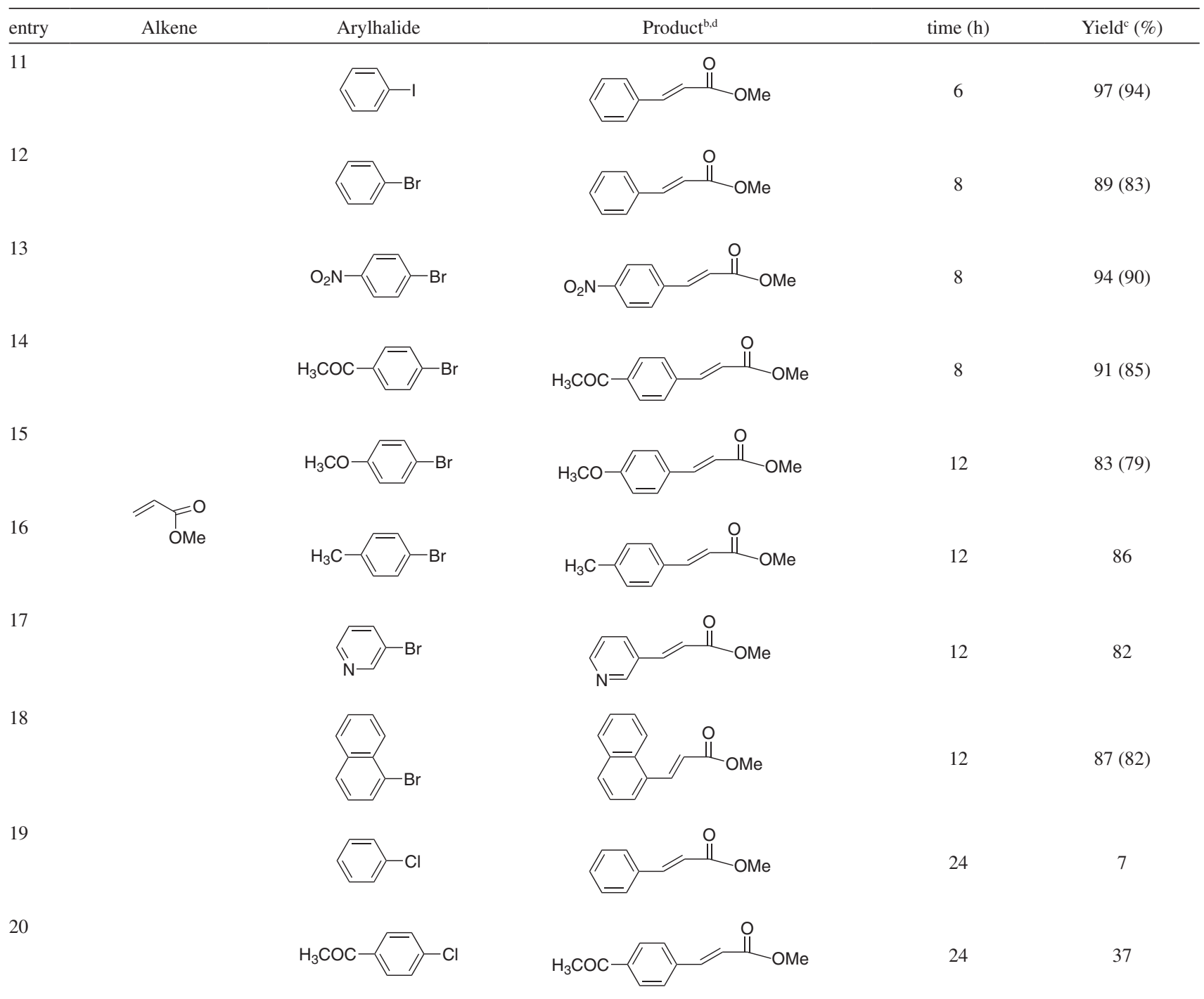

aReaction conditions: arylhalide $(1.0 \mathrm{mmol})$, alkene $(2.0 \mathrm{mmol}), \mathrm{K}_{2} \mathrm{CO}_{3}(2.0 \mathrm{mmol})$, DMF $(6 \mathrm{~mL})$, catalyst $(0.5 \mathrm{~mol} \%$ of Pd); All the reactions were carried out in air. ${ }^{b}$ Products were identified by comparison of their GC MS and ${ }^{1} \mathrm{H}$ NMR spectral data those reported in the literature (whenever possible). ${ }^{\circ}$ Yield of the reactant was determined by GC and GC MS analysis using dodecane as internal standard. The isolated yields are given in parentheses. ${ }^{\mathrm{d}}$ In all the coupling reactions, only $E$-stereochemistry was observed.

Table 3. Comparison of catalytic activity of the present catalyst in the Heck cross-coupling reaction with its homogeneous analogue and other related reported systems

\begin{tabular}{lcccc}
\hline Reaction & Catalyst & Reaction conditions & Yield $(\%)$ & Ref. \\
\hline 4-bromo nitrobenzene + styrene & $\mathrm{PS}\left[\left(\mathrm{C}_{6} \mathrm{H}_{4} \mathrm{CH}=\mathrm{N}\right) \mathrm{Pd}(\mathrm{OAc})\right]_{2}$ & $\mathrm{~K}_{2} \mathrm{CO}_{3}, \mathrm{DMF}, 0.5 \mathrm{~mol} \%$ of $\mathrm{Pd}, 90{ }^{\circ} \mathrm{C}, 8 \mathrm{~h}$ & 97 & This work \\
& {$\left[\left(\mathrm{C}_{6} \mathrm{H}_{4} \mathrm{CH}=\mathrm{N}\right) \mathrm{Pd}(\mathrm{OAc})\right]_{2}$} & $\mathrm{~K}_{2} \mathrm{CO}_{3}, \mathrm{DMF}, 0.5 \mathrm{~mol} \%$ of $\mathrm{Pd}, 90{ }^{\circ} \mathrm{C}, 8 \mathrm{~h}$ & 92 & This work \\
& $\mathrm{Pd}-\mathrm{PMMA}$ & $\mathrm{Et}_{3} \mathrm{~N}, \mathrm{DMF}, 1 \mathrm{wt} \%$ of Pd, $100{ }^{\circ} \mathrm{C}, 8 \mathrm{~h}$ & 84 & 49 \\
& $\mathrm{MCM}-41-\mathrm{SH}-\mathrm{Pd}(0)$ & $\mathrm{Bu}_{3} \mathrm{~N}, \mathrm{NMP}, 0.015 \mathrm{mmol} \mathrm{Pd}, 1300^{\circ} \mathrm{C}, 12 \mathrm{~h}$ & 90 & 50 \\
\hline
\end{tabular}

of the reaction, the catalyst was recovered by simple filtration and washed with ethyl acetate followed by acetone then dried in reduced pressure at $40{ }^{\circ} \mathrm{C}$. The recovered catalyst was employed in the next run with further addition of substrates in appropriate amount under optimum reaction conditions, and no substantial loss of activity was observed up to seven cycles. It was also observed from the IR spectral studies that there was no change in the nature of the catalyst even after the seventh cycle. 


\section{Conclusions}

In summary, we have synthesized a simple heterogeneous palladium complex which is successfully employed as an excellent catalyst for Heck crosscoupling reactions. The catalyst is more efficient with respect to quantity of catalyst required, the yields obtained and a much wider range of substrates can be utilized including electron-rich, electron-deficient and electronically neutral aryl halides. The main advantages of the present catalyst are easy synthesis of the catalyst, phosphine free conditions as well as convenient handling due to insensitivity to air and moisture which allows the reactions to be conducted in the undried solvent under air. The catalyst is highly reusable and shows seven time reusability without appreciable decrease in its initial activity.

\section{Experimental}

\section{Materials}

All the reagents were analytical grade and used as such without further purification. Solvents were purified and dried according to standard procedures. Macroporous polystyrene beads cross linked with divinylbenzene, was purchased from Aldrich Chemical Company, USA. Palladium acetate and palladium chloride were procured from Arora Matthey and used as such. Other reagents were purchased from Merck.

A Perkin-Elmer, USA, 2400C elemental analyzer was used to collect microanalytical data $(\mathrm{C}, \mathrm{H}$ and $\mathrm{N})$. The metal content in the polymer-anchored complex was analyzed using a Varian, USA, AA240 atomic absorption spectrophotometer (AAS). The reaction products were analyzed by Varian, USA, 3400 gas chromatograph equipped with a 30m CP-SIL8CB capillary column and a flame ionization detector. All reaction products were identified by using an Agilent, USA, GC MS (QP-5050). Surface morphology of functionalized polystyrene ligand and metal complex were analyzed using a scanning electron microscope (SEM) (ZEISS EVO40, England) equipped with EDX facility. The thermal stability of the immobilized catalyst was determined using a Mettler Toledo, Switzerland, TGA/DTA 851. The FTIR spectra of the immobilized catalyst were recorded on a PerkinElmer, USA, FTIR 783 spectrophotometer using $\mathrm{KBr}$ pellets. Diffuse reflectance UV-Vis spectra was taken using a Shimadzu, Japan, UV-2401PC double beam spectrophotometer having an integrating sphere attachment for solid samples.

\section{General experimental procedure for Heck reaction}

A mixture of aryl halide (1.0 mmol), alkene $(2.0 \mathrm{mmol})$, $\mathrm{K}_{2} \mathrm{CO}_{3}(2.0 \mathrm{mmol}), \mathrm{DMF}(6 \mathrm{~mL})$ and $1.0 \mathrm{~mol} \%$ of catalyst was stirred at $90{ }^{\circ} \mathrm{C}$ under air. To study the progress of the reaction, the mixtures were collected at different time interval and quantified by GC analysis. At the end of the reaction, the catalyst was separated by simple filtration. Filtrate was dried over sodium sulfate $\left(\mathrm{Na}_{2} \mathrm{SO}_{4}\right)$, filtered, concentrated and the residue was purified by flash column chromatography on silica gel. The product was analyzed by GC MS. All the prepared compounds are known and compared with authentic sample.

\section{Recovery and reuse of the catalyst}

The Heck reaction was carried out with 4-bromonitrobenzene $(1.0 \mathrm{mmol})$, styrene $(2.0 \mathrm{mmol}), \mathrm{K}_{2} \mathrm{CO}_{3}$ $(2.0 \mathrm{mmol})$ and catalyst $(0.5 \mathrm{~mol} \%$ of $\mathrm{Pd})$ in $\mathrm{DMF}$ $(6 \mathrm{~mL})$. Each reaction mixture was stirred at $90{ }^{\circ} \mathrm{C}$ in air atmosphere. After completion of the reaction, the mixture was cooled and the catalyst was separated from the liquid mixture by filtration. The filtrate was analyzed by CG to determine the yield of the product. The recovered catalyst was washed thoroughly with ethyl acetate and acetone and dried under reduced pressure at $40{ }^{\circ} \mathrm{C}$. The catalyst was totally recovered. From AAS analysis it is seen that the metal content of the recovered catalyst remained almost identical to that of fresh catalyst. After that, the recovered catalyst was reused for the next reaction under the same reaction conditions as mentioned above.

\section{Acknowledgments}

We acknowledge the Department of Science and Technology (DST), Council of Scientific and Industrial Research (CSIR) and the University Grant Commission (UGC), New Delhi, India for funding. One of the authors, K.T., is thankful to the University Grants Commission (Eastern Region), India, for financial support. We also thank the DST and UGC, New Delhi, India for providing instrumental support under the FIST and SAP program.

\section{References}

1. Alonso, F.; Beletskaya, I. P.; Yus, M.; Tetrahedron 2005, 61, 11771.

2. Beletskaya, I. P.; Cheprakov, A. V.; Chem. Rev. 2000, 100, 3009.

3. Dounay, A. B.; Overman, L. E.; Chem. Rev. 2003, 103, 2945.

4. Burke, T. R.; Liu, D.-G.; Gao, Y.; J. Org. Chem. 2000, 65, 6288.

5. Haberli, A.; Leumann, C. J.; Org. Lett. 2001, 3, 489. 
6. Oestreich, M.; The Mizoroki-Heck Reaction, Wiley: Chichester, 2009.

7. Eisenstadt, A.; Palladium in Catalysis of Organic Reactions, ed. Herkes, F.E.; Dekker, M. New York, 1998.

8. Reetz, M. T.; Lohmer, G.; Schwickardi, R.; Angew. Chem., Int. Ed. 1997, 36, 1526.

9. Aydemir, M.; Baysal, A.; Öztürk, G.; Gümgüm, B.; Appl. Organomet. Chem. 2009, 23, 108.

10. Akba, O.; Durap, F.; Aydemir, M.; Baysal, A.; Gümgüm, B.; Özkar, S.; J. Organomet. Chem. 2009, 694, 731.

11. Zotto, D. L.; Zangrando, E.; Baratta, W.; Felluga, A.; Martinuzzi, P.; Rigo, P.; Eur. J. Inorg. Chem. 2005, 23, 4707.

12. Barau, A.; Budarin, V.; Caragheorgheopol, A.; Luque, R.; Macquarrie, D. J.; Prelle, A.; Teodorescu, V. S.; Zaharescu, M.; Catal. Lett. 2008, 124, 204.

13. Heck, R. F.; Nolley, J. P.; J. Org. Chem. 1972, 37, 2320.

14. Plevyak, J. E.; Heck, R. F.; J. Org. Chem. 1978, 43, 2454.

15. Nicolaou, K. C.; Bulger, P. G.; Sarlah, D.; Angew. Chem., Int. Ed. 2005, 44, 4442.

16. Brase, S.; De Meijere, A.; Metal-Catalyzed Cross-Coupling Reactions, $2^{\text {nd }}$ ed., de Meijre, A.; Diederich, F., eds.; WileyVCH: Weinheim, 2004.

17. Barder, T. E.; Walker, S. D.; Martinelli, J. R.; Buchwald, S. L.; J. Am. Chem. Soc. 2005, 127, we 4685 .

18. Akba, O.; Durap, F.; Aydemir, M.; Baysal, A.; Gümgüma, B.; Özkar, S.; J. Organomet. Chem. 2009, 694, 731.

19. Surawatanawong, P.; Fan, Y.; Hall, M. B.; J. Organomet. Chem. 2008, 693, 1552.

20. Wang, Y. D.; Dutia, M.; Floyd, M. B.; Prashad, A. S.; Berger, D.; Lin, M.; Tetrahedron 2009, 65, 57.

21. Dupont, J.; Pfeffer, M.; Spencer, J.; Eur. J. Inorg. Chem. 2001, 1917.

22. Bedford, R. B.; Chem. Commun. 2003, 1787.

23. Herrmann, W. A.; Angew. Chem., Int. Ed. 2002, 41, 1290.

24. Dai, M.; Liang, B.; Wang, C.; Chen, J.; Yang, Z.; Org. Lett. 2004, 6, 221.

25. Yang, D.; Chen, Y.-C.; Zhu, N.-Y.; Org. Lett. 2004, 6, 1577.

26. Yang, Y.-C.; Luh, T.-Y.; J. Org. Chem. 2003, 68, 9870.

27. Yao, C.; Li, H.; Wu, H.; Liu, Y.; Wu, P.; Catal. Commun. 2009, 10, 1099.
28. Evangelisti, C.; Panziera, N.; Pertici, P.; Vitulli, G.; Salvadori, P.; Battocchio, C.; Polzonetti, G.; J. Catal. 2009, 262, 287.

29. Demel, J.; Sujandi, Park, S.-E.; Cejka, J.; Stepnicka, P.; J. Mol. Catal. A: Chem. 2009, 302, 28.

30. Calo, V.; Nacci, A.; Monopoli, A.; Fornaro, A.; Sabbatini, L.; Cioffi, N.; Ditaranto, N.; Organometallics 2004, 23, 5154.

31. Buyn, J. W.; Lee, Y. S.; Tetrahedron Lett. 2004, 45, 1837.

32. Lin, C.-A.; Luo, F. T.; Tetrahedron Lett. 2003, 44, 7565.

33. Luo, F. T.; Xue, C.; Ko, S.-L.; Shao, Y.-D.; Vvu, C.-J.; Kuo, Y.-M.; Tetrahedron 2005, 690, 4648.

34. Kim, J. H.; Kim, J. W.; Shokouhimehr, M.; Lee, Y. S.; J. Org. Chem. 2005, 70, 6714.

35. Islam, M.; Bose, A.; Mal, D.; Saha, C. R.; J. Chem. Res. 1998, 44.

36. Islam, S. M.; Bose, A.; Palit, B. K.; Saha, C. R.; J. Catal. 1998, 173, 268 .

37. Islam, S. M.; Mondal, P.; Roy, A. S.; Mondal, S.; Hossain, D.; Tetrahedron Lett. 2010, 51, 2067.

38. Islam, S. M.; Mondal, P.; Roy, A. S.; Mondal, S.; Mobarak, M.; J. Chem. Res. 2009, 756.

39. Stephens, T. A.; Wilkinson, G.; Inorg. Nucl. Chem. 1967, 29, 2122.

40. Onue, H.; Moritani, I.; J. Organomet. Chem. 1972, 43, 431.

41. Durig, J. R.; Layton, R.; Sink, D. W.; Mitchell, B. R.; Spectrochim. Acta 1965, 21, 1367.

42. Mino, T.; Shirae, Y.; Sasai, Y.; Sakamoto, M.; Fujita, T.; J. Org. Chem. 2006, 71, 6834.

43. Jung, I. G.; Son, S. U.; Park, K. H.; Chung, K.-C.; Lee, J. W.; Chung, Y. K.; Organometallics 2003, 22, 4715.

44. Firouzabadi, H.; Iranpoor, N.; Gholinejad, M.; Tetrahedron 2009, 65, 7079.

45. Lipshutz, B. H.; Ghorai, S.; Aldrichim. Acta 2008, 41, 59.

46. Lamblin, M.; Nassar-Hardy, L.; Hierso, J. C.; Fouquet, E.; Felpin, F. X.; Adv. Synth. Catal. 2010, 352, 33.

47. Beller, M.; Riermeier, T. H.; Eur. J. Inorg. Chem. 1998, 29.

48. Hahn, F. E.; Jahnke, M. C.; Gomez-Benitez, V.; MoralesMorales, D.; Pape, T.; Organometallics 2005, 24, 6458.

49. Song, D.; Yi, W.-B.; J. Mol. Catal. A: Chem. 2008, 280, 20.

50. Xu, Q.; Cai, M.; React. Funct. Polym. 2007, 67, 515.

Submitted: June 17, 2010

Published online: October 5, 2010 